\title{
SYNTHESIS, STRUCTURE AND LUMINESCENT PROPERTIES OF A MONONUCLEAR ZINC(II) COMPLEX WITH A BICOMPARTMENTAL LIGAND
}

\author{
MIHAI RĂDUCĂ ${ }^{\mathrm{a}}$, AUGUSTIN M. MĂDĂLAN ${ }^{\mathrm{a} *}$
}

\begin{abstract}
A mononuclear complex of $\mathrm{Zn}(\mathrm{II})$ with the Schiff base ligand derived from $\mathrm{o}$-vanillin and 2,2-dimethyl-1,3-diaminopropane $\left(\mathrm{H}_{2}\right.$ valdmpn) was obtained and structurally characterized by X-ray diffraction on single crystal. In the $\left[\mathrm{Zn}(\right.$ valdmpn $\left.)\left(\mathrm{H}_{2} \mathrm{O}\right)\right]$ complex the metal ion is pentacoordianated with a square pyramidal geometry. The luminescent properties of the complex were investigated in solid state and solution following the influence of the solvent.
\end{abstract}

Keywords: Zinc complexes, bicompartmental ligands, luminescence

\section{INTRODUCTION}

The reactions between $o$-vanillin and diamines can generate various Schiff base podands, that were extensively used as ligands. The morphologies of the resulting complexes depend basically on the flexibility or rigidity of the diamines. The relatively rigid podands derived from hydrazine, 4,4'-methylenedianiline or 4,4'-diaminodiphenyl ether are easily engaged in multiple bridging and helical binding modes [1-4]. Schiff-bases derived from o-vanillin and flexible diamines (ethylenediamine; 1,3-diaminopropane; 2,2dimethyl-1,3-diaminopropane) usually behave as bicompartmental ligands, allowing the synthesis of mono- and binuclear complexes (Scheme 1).

These ligands are suitable for the synthesis of heterobinuclear $3 d-4 f$ complexes [5-7] or 3d-3d' complexes [7-10]. In the 3d-4f complexes, the $3 d$ metal ion is located into the $\mathrm{N}_{2} \mathrm{O}_{2}$ compartment, while the oxophilic lanthanide cation occupies the larger, open $\mathrm{O}_{2} \mathrm{O}_{2}$ compartment. In the binuclear complexes, the phenoxo oxygen atoms act as bridges between the two metal ions. In mononuclear complexes with the metal ion hosted into the

\footnotetext{
a Inorganic Chemistry Department, Faculty of Chemistry, University of Bucharest, 23 Dumbrava Rosie, 020464-Bucharest, Romania

*Corresponding author: augustin.madalan@chimie.unibuc.ro
} 
$\mathrm{N}_{2} \mathrm{O}_{2}$ compartment, the larger vacant $\mathrm{O}_{2} \mathrm{O}_{2}$ compartment can act as a receptor not only toward other metal ions, but also toward hydrogen bond donors (e.g. the aqua ligand arising from another complex, identical [11] or different [12], amino groups [13-14], ammonium cation [15]).

In zinc-lanthanide complexes, this type of ligands can act as sensitizers for excitation of lanthanide ions (antenna effect), overcoming the disadvantage presented by the very small molar absorption coefficient of $f-f$ transitions [16]. In mononuclear zinc complexes, the metal ion (hosted into the $\mathrm{N}_{2} \mathrm{O}_{2}$ compartment) plays basically a structural role rigidifying the organic fragment, which can present photoluminescent properties [17].

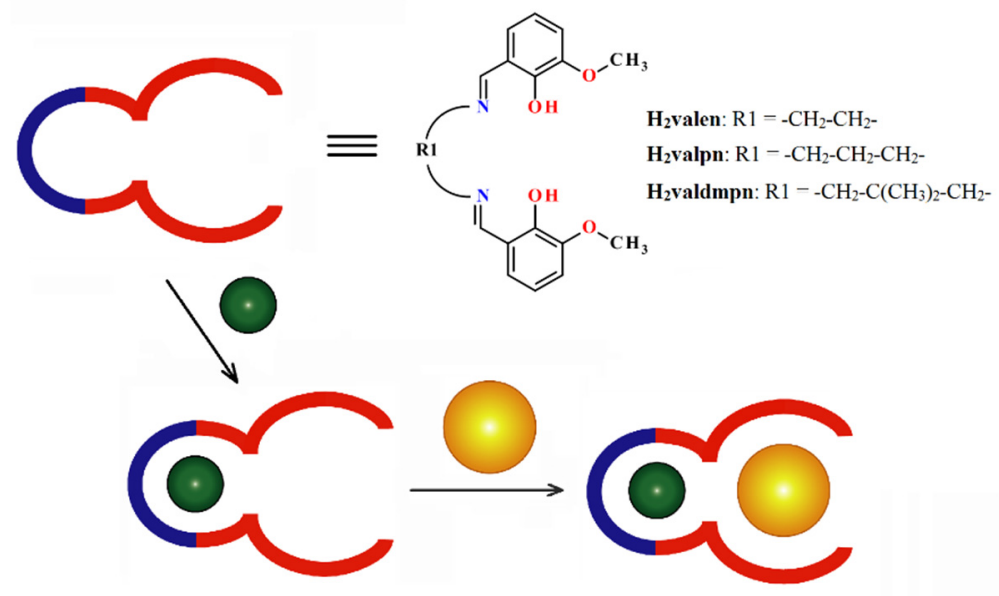

Scheme 1

In this paper, we report synthesis, structure and luminescent properties of a mononuclear complex of $\mathrm{Zn}$ (II) with the Schiff base ligand derived from o-vanillin and 2,2-dimethyl-1,3-diaminopropane. The luminescent properties of the complex were investigated both in solid state and solution. In solution, we were particularly interested by the solvent influence on the photoluminescent properties.

\section{RESULTS AND DISCUSSION}

Reaction of o-vanillin with 2,2-dimethyl-1,3-propylenediamine and $\mathrm{Zn}$ (II) nitrate in the presence of triethylamine affords yellow crystals, which were structurally characterized by X-ray diffraction on single crystal. The 
crystals contain mononuclear $\mathrm{Zn}(\mathrm{II})$ complexes, [ $\mathrm{Zn}($ valdmpn $)\left(\mathrm{H}_{2} \mathrm{O}\right)$ ], and crystallization water molecules. The general formula of the compound is [ $\mathrm{Zn}$ (valdmpn) $\left.\left(\mathrm{H}_{2} \mathrm{O}\right)\right] \cdot \mathrm{H}_{2} \mathrm{O}$. In the mononuclear complex, the zinc ion is pentacoordinated with a square-pyramidal geometry (Figure 1). The basal plane is formed by the two imino nitrogen atoms and the two phenoxo oxygen atoms of the Schiff base ligand. In the apical position is coordinated the oxygen atom of the water molecule. The basal bond lengths are $\mathrm{Zn} 1-\mathrm{N} 1=$ 2.119(5), Zn1-N2 = 2.109(5), Zn1-O2 = 2.017(5), and Zn1-O3 = 2.032(5) A,, longer than the apical one, $\mathrm{Zn} 1-\mathrm{O} 5=1.980(6) \AA$. The organic ligand has a 'butterfly' shape with the dihedral angle between the mean planes of the two aromatic fragments (including the imino and phenoxo groups) of $118.2^{\circ}$.
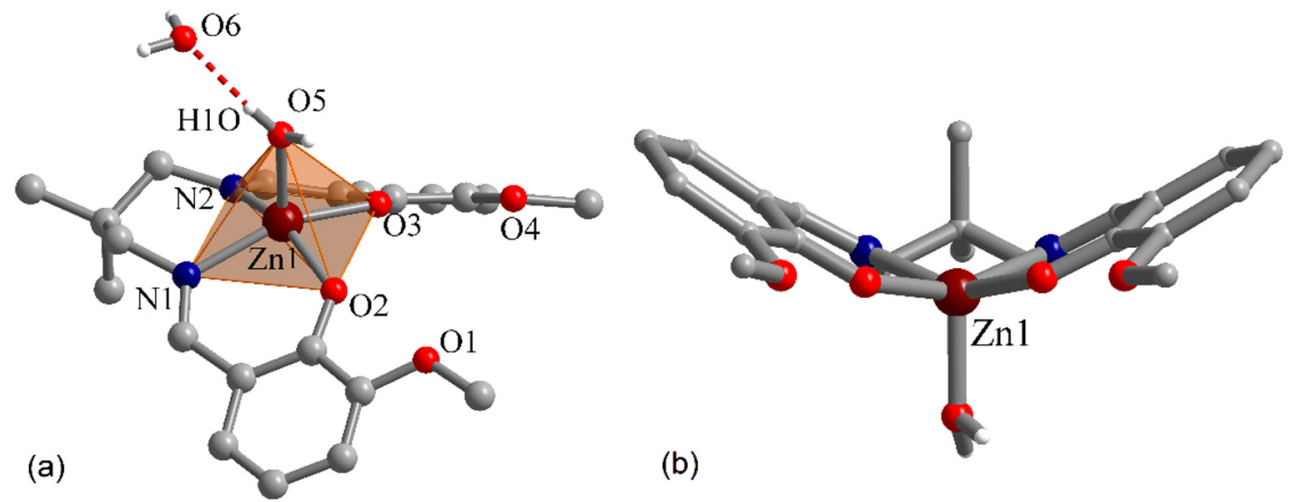

Figure 1. Perspective views of the asymmetric unit (a) and the mononuclear complex showing the 'butterfly' shape of the Schiff base ligand (b)

The coordinated water molecules are involved in hydrogen bonding with crystallization water molecules generating supramolecular double chains (Figure 2). Coordinated water molecules act only as hydrogen bond donors towards crystallization water molecules: $\mathrm{O} 5-\mathrm{H} 1 \mathrm{O} \cdots \mathrm{O} 6=1.82 \AA$, O5- $\mathrm{H} 2 \mathrm{O} \cdots \mathrm{O} 6$ ' $=1.94 \AA,<\mathrm{O} 5-\mathrm{H} 1 \mathrm{O} \cdots \mathrm{O} 6=167.8^{\circ}$ and $<\mathrm{O} 5-\mathrm{H} 2 \mathrm{O} \cdots \mathrm{O} 6^{\prime}=146.9^{\circ}$ (symmetry code: ' $=-0.5+x, 1.5-y,-z)$. The crystallization water molecules are hosted in the outer compartment of the organic ligand making donating bifurcated hydrogen interactions with the phenoxo and methoxy oxygen atoms. 


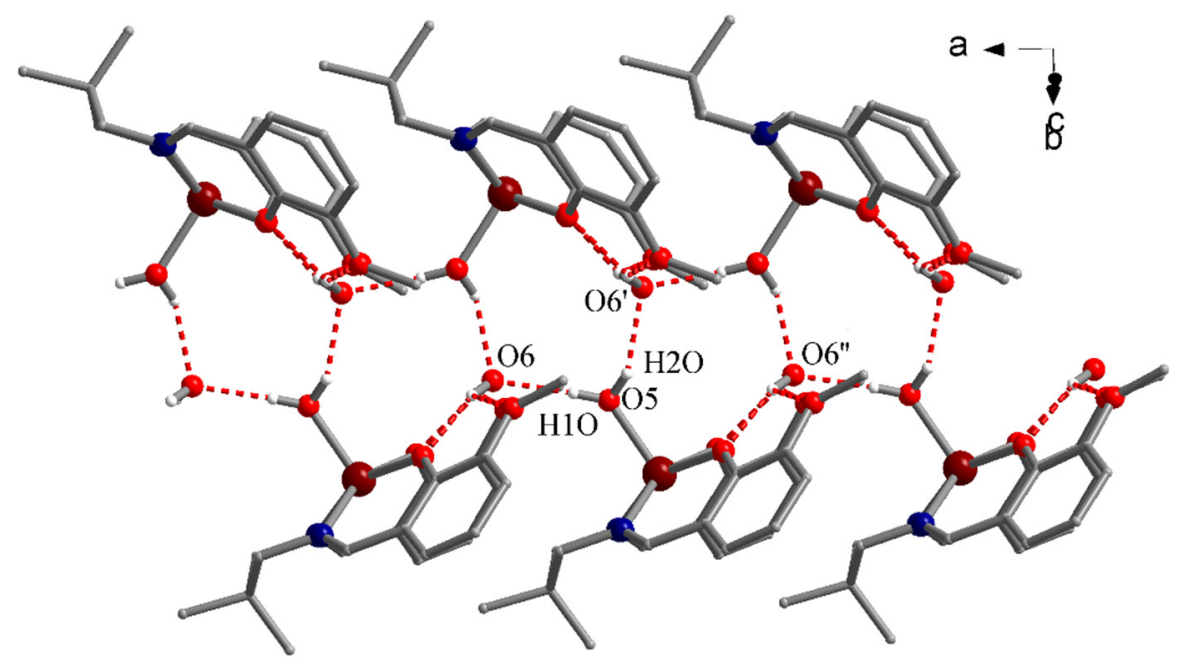

Figure 2. View of the supramolecular chain formed by hydrogen interactions (symmetry codes: ' $=-0.5+x, 1.5-y,-z$ and $"=-1+x, y, z$ )

An interesting feature of the packing is that the supramolecular double chains are oriented with 2,2-dimethyl-1,3-propylene fragments in the same direction and are running parallel along the crystallographic a axis (Figures 2 and 3 ). This type of packing explains the crystallization in a chiral space group, orthorhombic P212121.

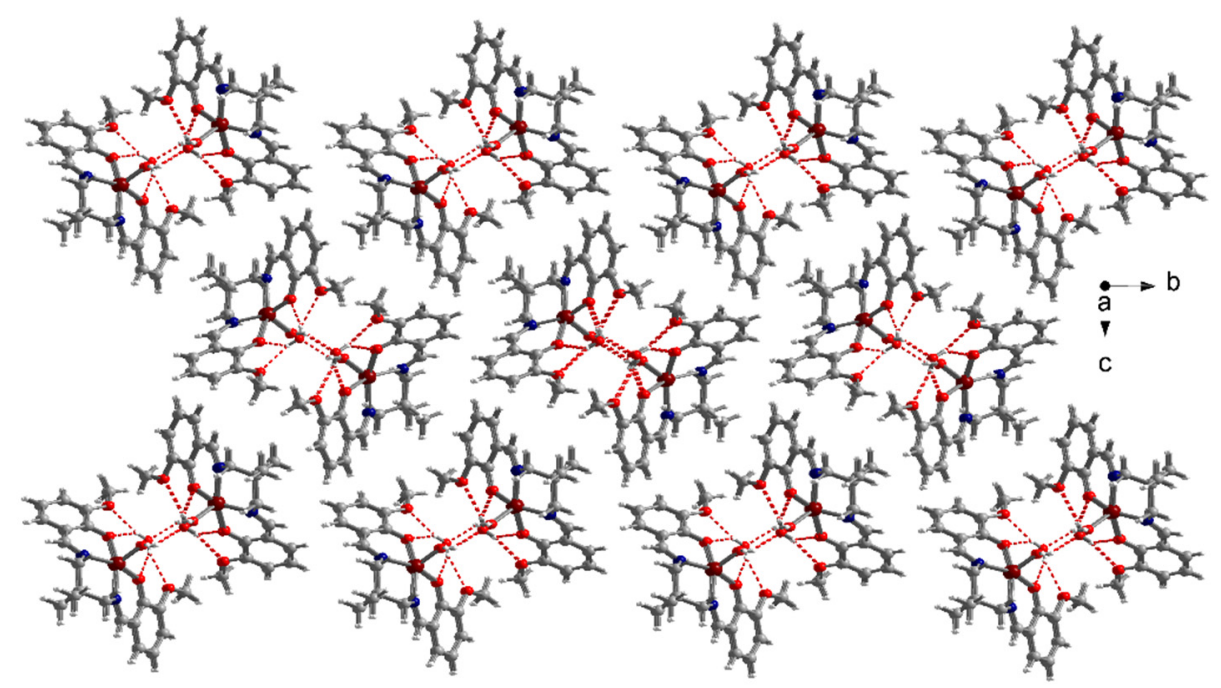

Figure 3. View of the packing diagram along the crystallographic a axis 


\section{Spectroscopic studies}

The electronic spectrum of compound $\left[\mathrm{Zn}(\right.$ valdmpn $\left.)\left(\mathrm{H}_{2} \mathrm{O}\right)\right] \cdot \mathrm{H}_{2} \mathrm{O}$, acquired over a wavelength range from 200 to $1800 \mathrm{~nm}$ on solid sample (using the diffuse reflectance technique), displays a band with the maximum at 410 $\mathrm{nm}$. The room temperature photoluminescence of crystalline compound [ $\mathrm{Zn}($ valdmpn $\left.)\left(\mathrm{H}_{2} \mathrm{O}\right)\right] \cdot \mathrm{H}_{2} \mathrm{O}$ was investigated using different wavelengths for excitation in the 330-430 $\mathrm{nm}$ range. The resulting emission spectrum displays an asymmetric band (tailed to the lower energy side) with a maximum at 460 $\mathrm{nm}$. The highest intensity of this band is obtained when $\lambda_{\mathrm{ex}}=350 \mathrm{~nm}$. The corresponding excitation spectrum $\left(\lambda_{\mathrm{em}}=460 \mathrm{~nm}\right)$ reveals a complex band within the 250-440 $\mathrm{nm}$ domain (Figure 4).

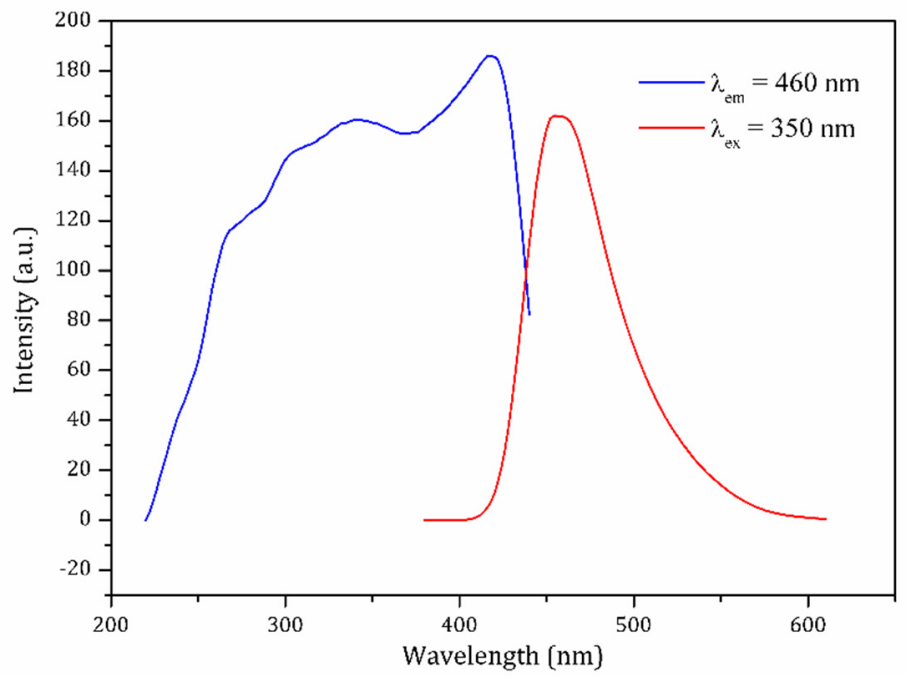

Figure 4. Emission (right) and excitation (left) spectra for the compound [Zn(valdmpn) $\left.\left(\mathrm{H}_{2} \mathrm{O}\right)\right] \cdot \mathrm{H}_{2} \mathrm{O}$

The influence of the solvent on the absorption properties (solvatochromism) was already studied for similar compounds [17]. We investigated the effect of the solvent on the emissive properties of the compound [ $\mathrm{Zn}($ valdmpn$\left.)\left(\mathrm{H}_{2} \mathrm{O}\right)\right]$. All solutions were prepared using $2.3 \mathrm{mg}$ of compound and $4 \mathrm{~mL}$ of solvent $(1.22 \mathrm{mM})$ and were ultrasonicated for 2 minutes for a proper solubilization. The solvents used were: dimethylsulfoxide (DMSO), tetrahydrofuran (THF), N,N-dimethylformamide (DMF), acetonitrile (ACN), chloroforme $\left(\mathrm{CHCl}_{3}\right)$, methanol $(\mathrm{MeOH})$, ethanol $(\mathrm{EtOH})$, 2-propanol (iPrOH), ethyl acetate (EtAc) and 2-methoxy ethanol (MeOEtOH). 
The emission spectra were recorded using $\lambda_{\mathrm{ex}}=350 \mathrm{~nm}$, and the respective pure solvents as references. The solvents used were of different polarities, protic ( $\mathrm{MeOH}, \mathrm{EtOH}, \mathrm{iPrOH}$ and $\mathrm{MeOEtOH}$ ) or aprotic (DMSO, THF, DMF, $\mathrm{ACN}, \mathrm{CHCl}_{3}$ and EtAc). The highest intensity of the emission was observed in the case of THF solution (more than double comparing with the next ones, DMF and EtAc - Figure 5). Using the less polar aprotic solvents, THF and EtAc, is also observed a blue shift of the emission with the maxima at $465 \mathrm{~nm}$ and $457 \mathrm{~nm}$, respectively. The emission maxima for the other solutions range between 471 and $479 \mathrm{~nm}$. For the ACN solution a quenching phenomenon is observed. In this context, no correlation can be done with the protic or aprotic nature of the solvent, since the highest and lowest intensities of the emission were observed for aprotic solvents (THF and ACN, respectively).
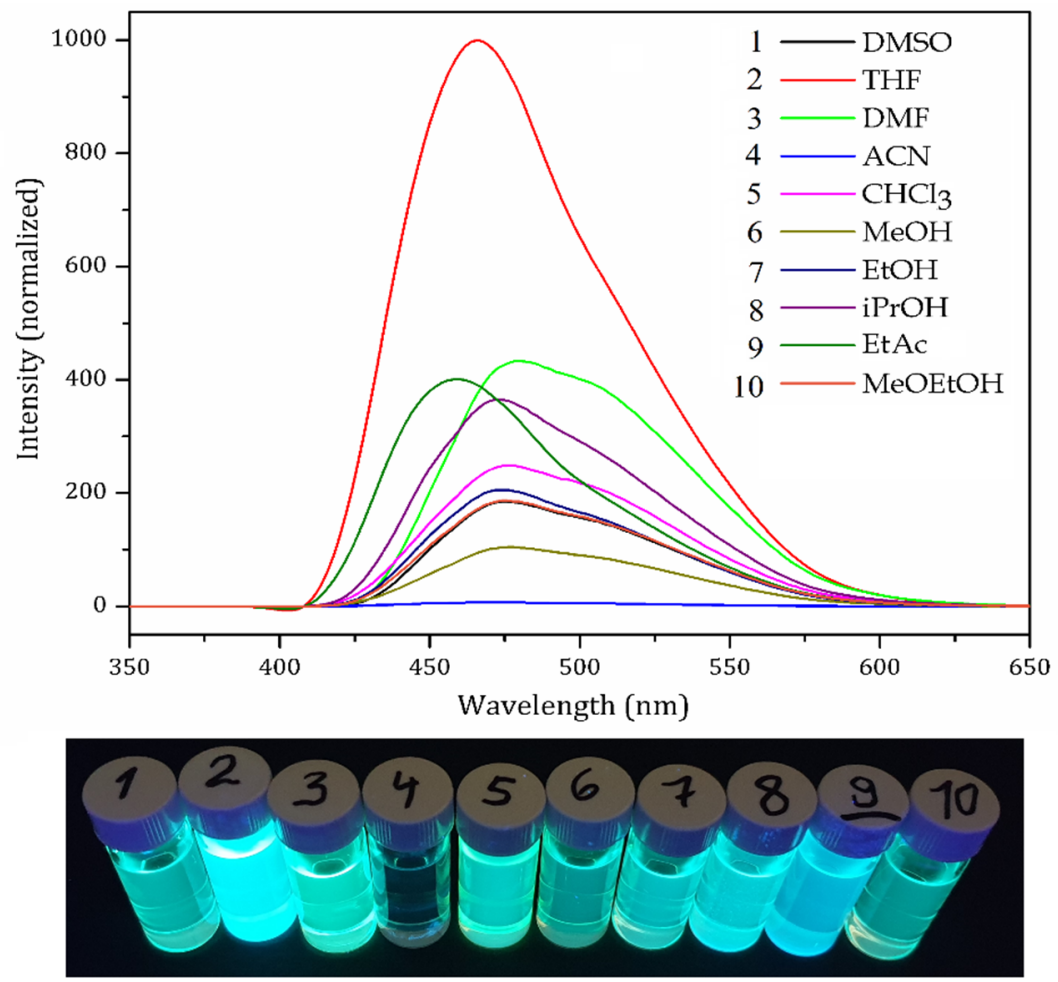

Figure 5. The emission spectra for $\left[\mathrm{Zn}(\right.$ valdmpn $\left.)\left(\mathrm{H}_{2} \mathrm{O}\right)\right]$ in different solvents $(1.22 \mathrm{mM})$ excited at $350 \mathrm{~nm}$ (top) and the comparative aspect of the solutions under $365 \mathrm{~nm}$ UV light (bottom) 


\section{CONCLUSIONS}

The mononuclear complex of $\mathrm{Zn}(\mathrm{II})$ with the bicompartmental Schiff base ligand derived from $o$-vanillin and 2,2-dimethyl-1,3-diaminopropane confirmed the ability of this type of complexes to act as receptor for hydrogen bond donors (a water molecule in this particular case). The hydrogen interactions between the water molecules coordinated to the $\mathrm{Zn}$ (II) ions and that ones hosted in the larger vacant $\mathrm{O}_{2} \mathrm{O}_{2}$ compartments of the complexes generate an oriented 1D supramolecular array. The photoluminescent properties of the complex are influenced by the solvent, but no clear correlations can be done with the polarity and protic or aprotic nature of the solvent.

\section{EXPERIMENTAL SECTION}

Synthesis. $5 \mathrm{mmol}$ of $\mathrm{Zn}\left(\mathrm{NO}_{3}\right)_{2} \cdot 6 \mathrm{H}_{2} \mathrm{O}$ were added to an ethanolic solution $(75 \mathrm{~mL})$ containing $10 \mathrm{mmol}$ of 3-methoxysalicylaldehyde and $5 \mathrm{mmol}$ of 2,2-dimethyl-1,3-propylenediamine. Subsequently $20 \mathrm{mmol}$ triethylamine were added. The mixture was stirred for 1 hour at $60^{\circ} \mathrm{C}$. The slow evaporation at room temperature of the resulting mixture affords yellow single crystals after 3-4 days. Selected IR data $\left(\mathrm{KBr}\right.$ pellet, $\left.\mathrm{cm}^{-1}\right): 3051(\mathrm{~m}), 2950(\mathrm{~m}), 1620$ (vs), $1546(\mathrm{w}), 1471(\mathrm{~s}), 1418(\mathrm{~s}), 1402(\mathrm{w}), 1390(\mathrm{w}), 1326(\mathrm{~m}), 1242(\mathrm{~m})$, $1222(\mathrm{~s}), 1070(\mathrm{~m}), 970(\mathrm{w}), 858(\mathrm{w}), 738(\mathrm{~m})$.

Physical measurements. The IR spectra ( $\mathrm{KBr}$ pellets) were collected on a Bruker Tensor 37 spectrophotometer in the $4000-400 \mathrm{~cm}^{-1}$ range. The UV-Vis-NIR spectra (diffuse reflectance technique) were recorded on a JASCO V-670 spectrophotometer. The fluorescence spectra were collected on a JASCO FP-6500 spectrofluorometer.

$X$-ray crystallography. Single crystal X-ray diffraction measurements were performed on a STOE IPDS II diffractometer operating with Mo-K $\alpha$ $(\lambda=0.71073 \AA) X$-ray tube with graphite monochromator. The structure was solved by direct methods and refined by full-matrix least squares techniques based on $F^{2}$. The non-H atoms were refined with anisotropic displacement parameters. Calculations were performed using SHELX-2014 crystallographic software package. A summary of the crystallographic data and the structure refinement is given in Table 1. CCDC reference number: 1952966. 
Table 1. Crystallographic data, details of data collection and structure refinement parameters for $\left[\mathrm{Zn}(\right.$ valdmpn $\left.)\left(\mathrm{H}_{2} \mathrm{O}\right)\right] \cdot \mathrm{H}_{2} \mathrm{O}$

\begin{tabular}{|c|c|}
\hline Compound & {$\left[\mathrm{Zn}\left(\right.\right.$ valdmpn)( $\left.\left.\mathrm{H}_{2} \mathrm{O}\right)\right] \cdot \mathrm{H}_{2} \mathrm{O}$} \\
\hline Chemical formula & $\mathrm{C}_{21} \mathrm{H}_{28} \mathrm{~N}_{2} \mathrm{O}_{6} \mathrm{Zn}$ \\
\hline$M\left(\mathrm{~g} \mathrm{~mol}^{-1}\right)$ & 469.82 \\
\hline Temperature $(\mathrm{K})$ & $173(2)$ \\
\hline Wavelength $(\AA)$ & 0.71073 \\
\hline Crystal system & Orthorhombic \\
\hline Space group & $P 212121$ \\
\hline$a(\AA)$ & $6.7049(4)$ \\
\hline$b(\AA)$ & $15.9853(11)$ \\
\hline$c(\AA)$ & $20.2309(14)$ \\
\hline$\alpha\left({ }^{\circ}\right)$ & 90 \\
\hline$\beta\left(^{\circ}\right)$ & 90 \\
\hline$\gamma\left(\left(^{\circ}\right)\right.$ & 90 \\
\hline$V\left(\AA^{3}\right)$ & $2168.3(2)$ \\
\hline Z & 4 \\
\hline$D_{\mathrm{c}}\left(\mathrm{g} \mathrm{cm}^{-3}\right)$ & 1.439 \\
\hline$\mu\left(\mathrm{mm}^{-1}\right)$ & 1.172 \\
\hline$F(000)$ & 984 \\
\hline Goodness-of-fit on $F^{2}$ & 0.937 \\
\hline Final $R_{1}, w R_{2}[/>2 \sigma(I)]$ & $0.0490,0.0629$ \\
\hline$R_{1}, w R_{2}$ (all data) & $0.1041,0.0765$ \\
\hline Largest difference in peak and hole $\left(\mathrm{e} \AA^{-3}\right)$ & $0.341,-0.510$ \\
\hline
\end{tabular}

The X-ray powder diffraction measurements (XRPD) were carried out on a Proto AXRD Benchtop using the $\mathrm{Cu}$-Ka radiation with a wavelength of $1.540593 \AA$ in the range $5-35^{\circ} 2 \theta$. In the figure 6 are presented the experimental and single-crystal simulated XRPD patterns of the compound $\left[\mathrm{Zn}(\right.$ valdmpn $\left.)\left(\mathrm{H}_{2} \mathrm{O}\right)\right] \cdot \mathrm{H}_{2} \mathrm{O}$ showing the purity of the solid sample. 


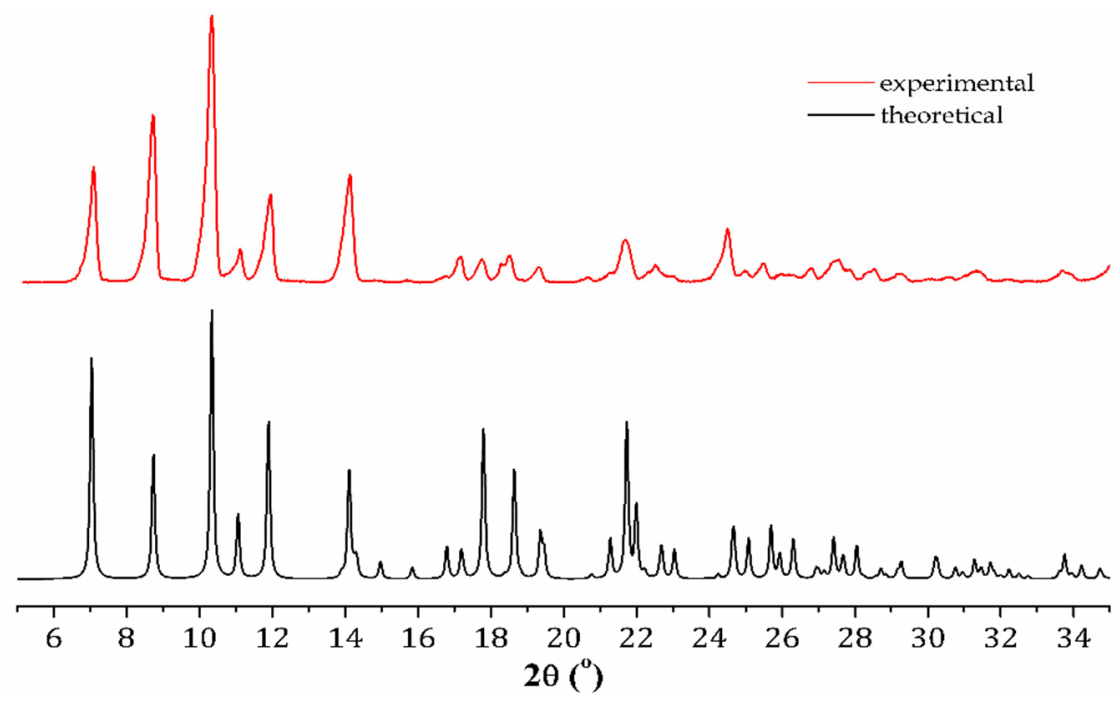

Figure 6. Comparison between the experimental (in red) and single-crystal simulated (in black) XRPD patterns of $\left[\mathrm{Zn}\left(\right.\right.$ valdmpn) $\left.\left(\mathrm{H}_{2} \mathrm{O}\right)\right] \cdot \mathrm{H}_{2} \mathrm{O}$

\section{ACKNOWLEDGMENTS}

Financial support from University of Bucharest (project 72/2013) is highly acknowledged.

\section{REFERENCES}

1. J. Wu; L. Zhao; P. Zhang; L. Zhang; M. Guo; J. Tang; Dalton Trans., 2015, 44, 11935-11942.

2. P. Cucos; F. Tuna; L. Sorace; I. Matei; C. Maxim; S. Shova; R. Gheorghe; A. Caneschi, M. Hillebrand; M. Andruh; Inorg. Chem., 2014, 53, 7738-7747.

3. D. Jiang; X. Yang; H. Chen; F. Wang; S. Wang; T. Zhu; L. Zhang; S. Huang; Dalton Trans., 2019, 48, 2206-2212.

4. G. Novitchi; J.-P. Costes, J.-P. Tuchagues; L. Vendier; W. Wernsdorfer; New J. Chem., 2008, 32, 197-200.

5. J.-P. Costes; F. Dahan; A. Dupuis; J.-P. Laurent; Inorg. Chem., 1996, 352400 2402.

6. M. Andruh; Chem. Commun., 2007, 2565-2577. 
7. M. Andruh; Chem. Commun., 2011, 47, 3025-3042.

8. D.G. Branzea; A. Guerri; O. Fabelo; C. Ruiz-Pérez; L.-M. Chamoreau; C. Sangregorio; A. Caneschi; M. Andruh; Cryst. Growth Des., 2008, 8, 941-949.

9. D.G. Branzea; L. Sorace; C. Maxim; M. Andruh; A. Caneschi; Inorg. Chem., 2008, 47, 6590-6592.

10. M. Nayak; R. Koner; H.-H. Lin; U. Flörke; H.-H. Wei; S. Mohanta; Inorg. Chem., 2006, 45, 10764-10773.

11. S. Nastase; F. Tuna; C. Maxim; C.A. Muryn; N. Avarvari; R.E.P. Winpenny; M. Andruh; Cryst. Growth Des., 2007, 7, 1825-1831.

12. A.M. Madalan; N. Avarvari; M. Andruh; New J. Chem.; 2006, 30, 521-523.

13. A.M. Madalan; C.D. Ene; Inorg. Chim. Acta, 2018, 475, 184-192.

14. M. Nayak; S. Sarkar; P. Lemoine; S. Sasmal; R. Koner; H.A. Sparkes; J.A.K. Howard; S. Mohanta; Eur. J. Inorg. Chem., 2010, 744-752.

15. A. Cucos; A. Ursu; A.M. Madalan; C. Duhayon; J.-P. Sutter; M. Andruh; CrystEngComm, 2011, 13, 3756-3766.

16. T.D. Pasatoiu; C. Tiseanu; A.M. Madalan; B. Jurca; C. Duhayon; J.P. Sutter; M. Andruh; Inorg. Chem., 2011, 50, 5879-5889.

17. S.S. Sreejith; N. Mohan; M.R. Prathapachandra Kurup; Polyhedron, 2017, 135, 278-295. 